\title{
ОЦЕНКА ВЛИЯНИЯ ПАНДЕМИИ НА ФИНАНСОВУЮ УСТОЙЧИВОСТЬ СТРОИТЕЛЬНЫХ ОРГАНИЗАЦИЙ
}

\author{
(c) 2021 Иззука Татьяна Борисовна \\ доцент, кандидат экономических наук \\ Департамент бизнес-аналитики Факультета налогов, аудита и бизнес-анализа \\ Финансовый университет при Правительстве Российской Федерации, Россия, Москва \\ E-mail: TBIzzuka@fa.ru \\ (c) 2021 Кулаженкова Аполлинария Юрьевна \\ студент 3 курса, группа У19-6у \\ Факультет налогов, аудита и бизнес-анализа \\ Финансовый университет при Правительстве Российской Федерации, Россия, Москва \\ E-mail: apollinaria_ku@mail.ru
}

В статье рассматривается оценка влияния пандемии на строительную отрасль. Строительная индустрия в России остается одной из самых стабильных и динамичных отраслей в экономике страны, несмотря на экономическую нестабильность внутри отрасли. Цель работы - проанализировать состояние отрасли на текущий момент и сделать выводы о последствиях, которые повлекла пандемия.

Коронавирусная инфекция и тенденции, происходящие на протяжении нескольких лет в данной отрасли, оказали серьезное воздействие на снижение темпов ввода нового жилья в стране. Замедление в отрасли обуславливается в основном из-за переноса сроков сдачи объектов, при условии, что девелоперы старались не приостанавливать строительство и выполнение работ.

Строительный бизнес в России хорошо развит только в тех регионах, где инвестируется больше средств. Именно этим организациям, расположенным ближе к столице, будет легче освоить денежные средства, которые планируется вложить в инфраструктуру в рамках национального проекта. В остальных регионах выше риски неэффективных расходов из-за отсутствия опыта работы над крупными проектами от местных подрядчиков и заказчиков.

Для устранения выявленных слабых мест в функционировании организации, укрепления уже устоявшихся механизмов, обеспечения необходимого контроля за организационной и финансовой деятельностью, выработки стратегии и тактики на будущее, прогнозирования изменения ключевых показателей и, в целом, положения строительной организации на современном рынке, необходимо проводить анализ её финансовой устойчивости. Проводимый анализ способен определить существующие отклонения по рассчитанным коэффициентам или показателям, нарушения в установленных нормах и правилах, дисбаланс между частями одного целого.

Оценка финансовой устойчивости, являющаяся одной из составляющих финансового анализа, указывает на проблемные места, которые есть у организации, а также на возможные пути развития и улучшения. На её основе осуществляется дальнейшая разработка стратегии деятельности организации, а также контроль над динамикой ключевых показателей и управленческими решениями, принимаемыми внутри организации.

На основании проведенного исследования, авторами были сделаны выводы о состоянии строительной отрасли, а также приведены рекомендации по решению текущих проблем.

Ключевые слова: строительство, строительная отрасль, последствия пандемии, тенденции, финансовая устойчивость, платежеспособность, динамика, финансовые коэффициенты.

\section{Введение}

Финансовая устойчивость - способность организации к развитию, эффективной деятельности и конкуренции и может носить устойчивый, неустойчивый и кризисный характер. Такая деятельность достигается при условии баланса между доходами и расходами, между собственным и заёмным капиталом, между активами и пассивами бухгалтерского баланса.

Пандемия в связи с распространением ви- 
руса COVID-19 внесла множество коррективов в привычный образ жизни и вызвала кризис на многих рынках. Так как строительство имеет как прямое, так и косвенное влияние на все из них, необходимо рассмотреть, как коронавирусные ограничения повлияли на данную отрасль, чтобы оценить возможные тенденции в ее последующем развитии.

Цель данной работы - оценить влияние пандемии на финансовую устойчивость строительных организаций.

При анализе финансовой устойчивости строительных организаций в статье рассчитаны и проанализированы не только абсолютные показатели, присутствующие в строках форм бухгалтерской отчетности, но и относительные. Использование относительных показателей при расчетах можно объяснить тем, что абсолютные показатели трудно приводимы к сопоставимому виду в условиях инфляции. Чтобы оценить степень риска и спрогнозировать банкротство, относительные показатели сравниваются с установленными и общепринятыми нормами. Большое значение имеет межхозяйственный сравнительный анализ коэффициентов финансовой устойчивости между организациями. Сравнение относительных данных отчетного периода с прошлыми периодами необходимо для того, чтобы определить положительная или отрицательная складывается динамика, а также для того, чтобы изучить тенденцию изменения финансового состояния организации.

\section{Практическая часть}

Строительная отрасль является одной из основных как по экономическому, так и по социальному факторам. В 2020 году в общем объеме ВВП доля строительства составила $5,7 \%$, что на
2,3\% больше, чем в 2019 году.

С общественной точки зрения строительство необходимо для безопасности и комфортной жизни населения, затрагивая каждую сферу общества. И поэтому роль финансовой устойчивости данного сектора имеет значительное влияние на экономику стран в целом.

Для анализа изменения финансовой устойчивости были взяты данные финансовой отчетности 3 крупнейших застройщиков России, входящих в ТОП-10 по объему текущего строительства, согласно данным «Единого ресурса застройщиков» (ГК «ЛСР», ООО «Сэтл Групп», ГК «ПИК»), а также 5 застройщиков с объемом текущего строительства меньше 10000 м3 (AО «Воронежстрой», АО «СЗ Благовещенскстрой», АО «ПСО-13»). Данная группировка позволит оценить изменения как среди «гигантов» строительного рынка, так и представителей малого бизнеса на региональных рынках, так как положение этих групп на общем рынке строительства значительно отличается.

В рамках анализа финансовой устойчивости были рассчитаны следующие показатели по каждой компании за период 2018-2020 гг. по методике Донцовой Л. В. и Никифоровой Н. А. [2, с. 25]:

В среднем по рынку крупных застройщиков можно сделать вывод, что негативно на коэффициент капитализации пандемия не повлияла, так как обязательное введение эскроу-счетов в 2019 году привело к росту как заемного капитала, так и собственного за счет роста прибыли, связанного с ростом цен на объекты недвижимости из-за исчезновения рисков у дольщиков при инвестированиях на начальных этапах строительства. В 2020 году снижение коэффициента капитализации продолжилось также за счет ро-

\footnotetext{
- Обрабатывающие производства

- Торговля, ремонт автотранспорта и мотоциклов

- Деятельность по операциям с недвижимым имуществом

- Добыча полезных икопаемых

- Государственное управление и обеспечение военной безопасности; социальное обеспечение - Транспортировка и хранение

- Строительство

- Иные отрасли
}

Puc. 1. Структура ВВП за 2020 г. по отраслям экономики, \% Источник: Росстат 
Таблица 1. Показатели финансовой устойчивости по методике Донцовой Л. В., Никифоровой Н. А.

\begin{tabular}{|l|l|}
\hline \multicolumn{1}{|c|}{ Показатель финансовой устойчивости } & \multicolumn{1}{c|}{ Расчет показателя } \\
\hline Коэффициент капитализации & Заемные средства/Собственный капитал \\
\hline $\begin{array}{l}\text { Коэффициент обеспеченности оборотных активов } \\
\text { собственными средствами }\end{array}$ & $\begin{array}{l}\text { (Собственный капитал - Внеоборотные активы)/ } \\
\text { Оборотные активы }\end{array}$ \\
\hline Коэффициент финансовой независимости & Собственный капитал/Общие обязательства \\
\hline Коэффициент финансирования & Собственный капитал/Заемные средства \\
\hline Коэффициент финансовой устойчивости & $\begin{array}{l}\text { (Собственный капитал + Долгосрочные заемные } \\
\text { средства)/Общие обязательства }\end{array}$ \\
\hline
\end{tabular}

Источник: Донцова Л. В., Никифорова Н.А. «Анализ финансовой отчетности»

ста выручки, приведшего к увеличению нераспределенной прибыли в составе собственного капитала организаций, что отчасти можно объяснить льготным ипотечным кредитованием в рамках мер по поддержке строительной отрасли в период пандемии, отразившегося на росте цен на рынке недвижимости.

Схожая динамика наблюдается и среди мелких застройщиков, как показано на рисунке 26.

Таким образом, можно сделать вывод, что в период пандемии, несмотря на общий кризис, растет инвестиционная привлекательность как крупных, так и мелких застройщиков в связи с увеличением их финансирования за счет собственных средств - данный коэффициент обратен коэффициенту капитализации, и в сложившейся ситуации его средние значения по обеим группам увеличиваются.

При этом рост прибыли строительных организаций привел к росту их автономии, что выражено в положительной динамике коэффициента финансовой независимости, как показано на рисунке 3 a.

В среднем по крупным застройщикам сред- нее значение коэффициента растет. При этом необходимо отметить, что среди представителей малого бизнеса среднее значение показателей хоть и снизилось в 2019 году, что связано с резким снижением по одной из компаний, абсолютные значения данного коэффициента выше, чем по крупнейшим компаниям отрасли. Возможной причиной такой ситуации могут служить высокие требования банков к финансовым показателям организаций-застройщикам, деятельность которых они теперь в основном финансируют в связи с введением эскроу-счетов. И, соответственно, малому бизнесу необходимо наращивать собственные источники для финансирования строительства, так как не все банки готовы предоставлять им кредиты.

Пропорционально динамике коэффициента автономии наблюдается динамика коэффициента обеспеченности оборотных активов собственными средствами, как показано на рисунке 4.

Данная динамика свидетельствует о том, что рынок строительства остается даже в период пандемии одним из самых стабильных и состоятельных. Причем стоит отметить, что для

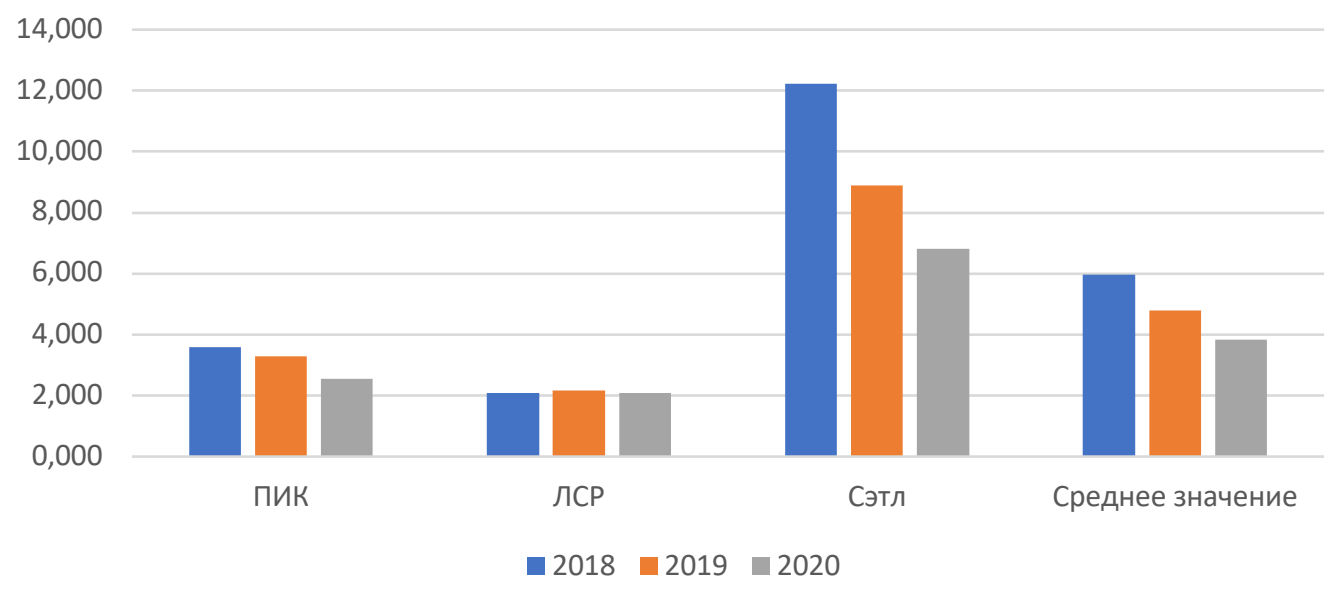

Puc. 2а. Динамика коэффициента капитализации крупных строительных организаций за 2018-2020 гг.

Источник: составлено авторами 


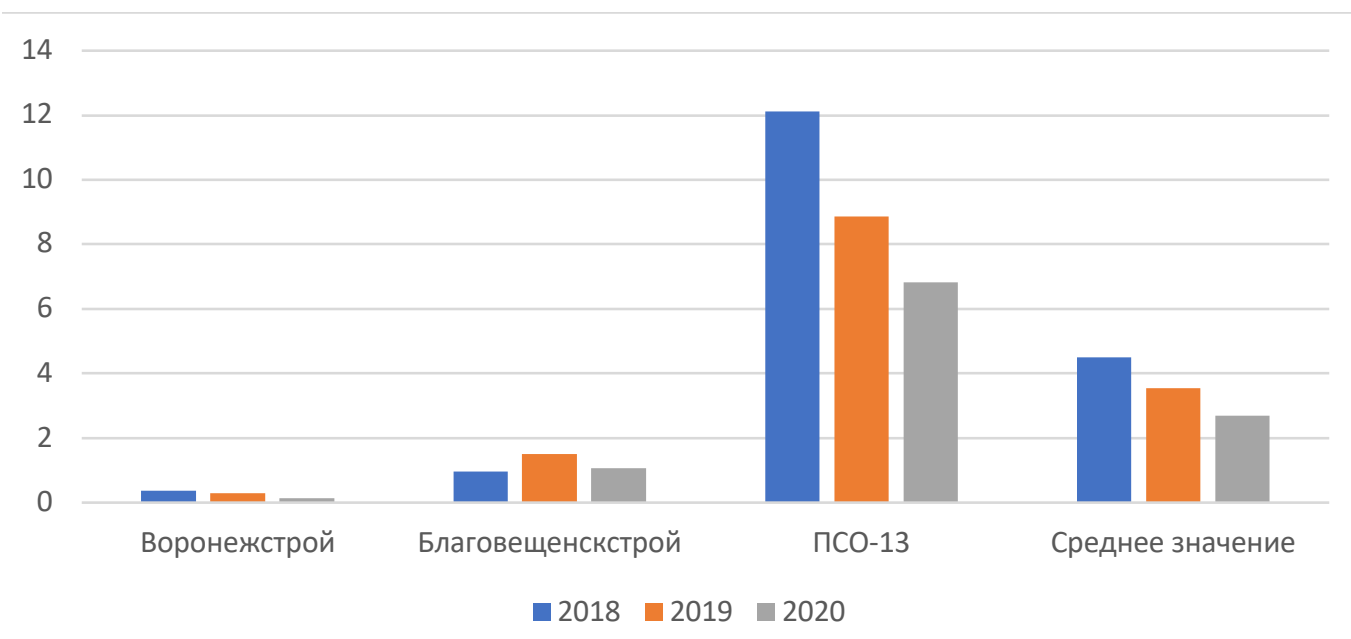

Puc. 2б. Динамика коэффициента капитализации малых строительных организаций за 2018-2020 гг.

Источник: составлено авторами

строительной отрасли отрицательные значения данного показателя не редкость, так как зачастую внеоборотные активы отрасли достаточно дорогостоящие, а деятельность в основном финансируется внешними источниками. Так что положительные значения и их динамика на данный момент говорят о том, что отрасль на сегодня менее многих других подвержена влиянию пандемии.

В среднем по крупным компаниям показатель финансовой устойчивости растет, несмотря на некоторое отклонение индивидуальных значений от среднего. Данный вывод следует и из предыдущих расчетов. Также важно отметить, что, несмотря на более высокое значение коэффициентов обеспеченности оборотных активов, финансовой независимости и финансирования по малому бизнесу, более высокие показатели финансовой устойчивости характерны для крупных российских девелоперов, так как именно их деятельность банки готовы финансировать больше, чем средние и малые предприятия. Связано это с более высокими финансовыми показателями топовых застройщиков и, как следствие, более низкими рисками при предоставлении им заемного капитала.

В рамках финансовой отчетности за 2020 год и проведенного на ее основе анализа финансовой устойчивости можно сделать вывод, что строительство остается одной из самых стабильных и инвестиционно-привлекательных отраслей российской экономике. При этом сниже-

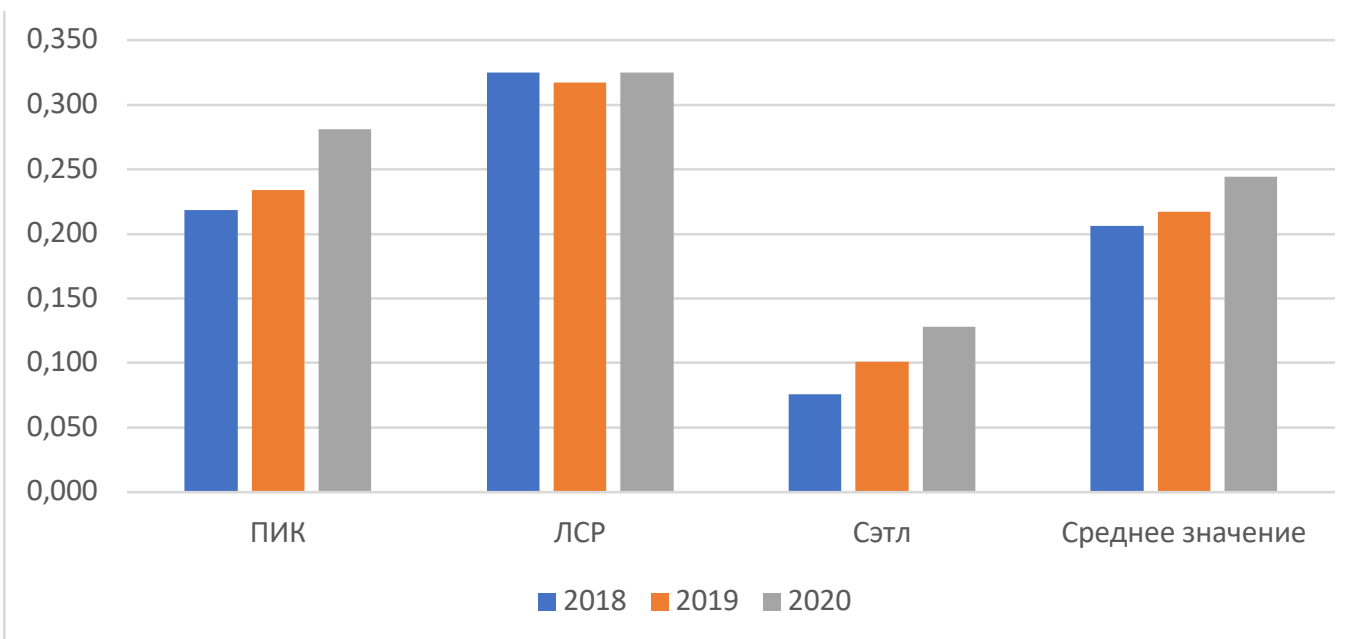

Puc. За. Динамика коэффициента финансовой независимости крупных строительных организаций за 2018-2020 гг. Источник: составлено авторами 


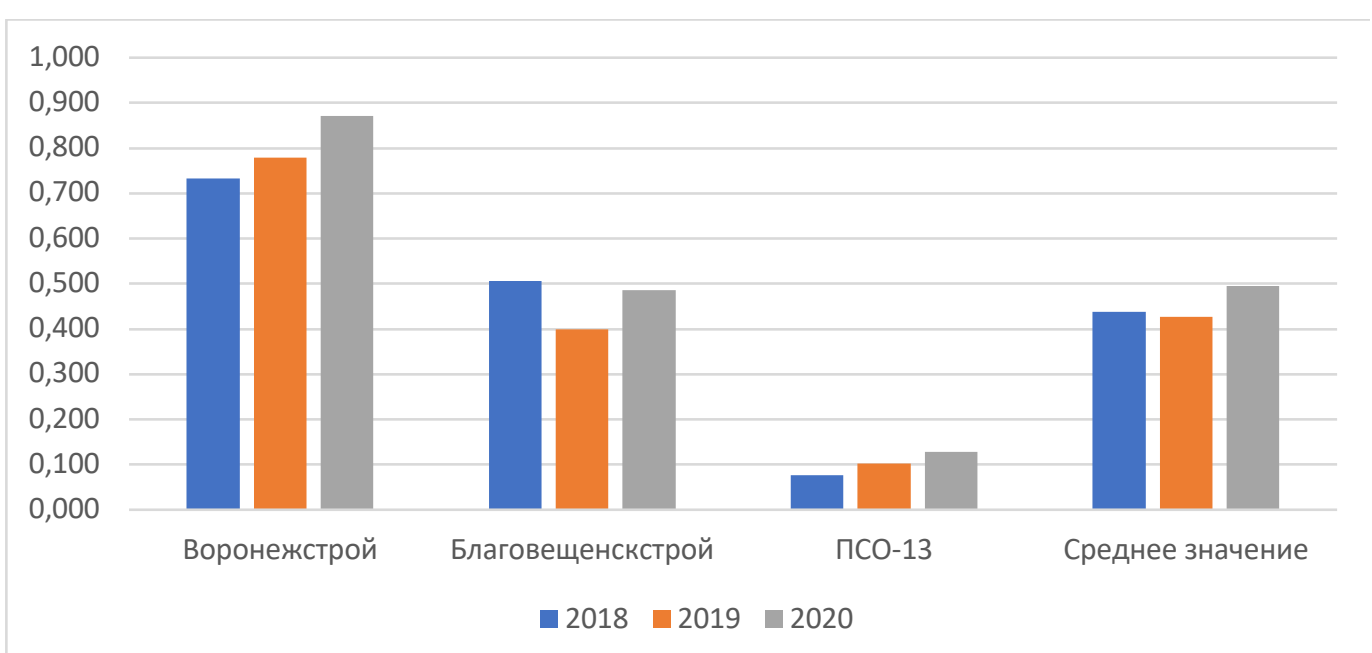

Puc. 3б. Динамика коэффициента финансовой независимости малых строительных организаций за 2018-2020 гг.

Источник: составлено авторами

ние ипотечной ставки позволило сохранить на рынке позиции как крупных девелоперов, так и представителей малого бизнеса. Но, учитывая данный фактор, возникает вопрос, будет ли и далее расти спрос на недвижимость. Мы разделяем мнение, что продолжение применения льготных ставок может привести к ситуации мирового кризиса 2007-2008 года, связанного с уже образовываемым «пузырем», когда доходы населения растут неравномерно в сравнении с объемом приобретаемых объектов строительства. (что обусловлено кризисной ситуацией в связи c COVID-19).
Представленные диаграммы подтверждают предположение, что льготное ипотечное кредитование повлекло резкий рост объема предоставляемой ипотеки. При этом стоит отметить, что в течение 2 лет происходит перманентный рост задолженности по ипотечному жилищному кредитованию. Пик просроченной задолженности приходится на вторую половину 2020 года первую половину 2021 года, когда была так называемая «вторая волна». Но, так как в 2021 году ограничительные меры в бизнесе стали ослабляться, то это, на наш взгляд, привело к росту доходов населения и, как следствие, к сни-

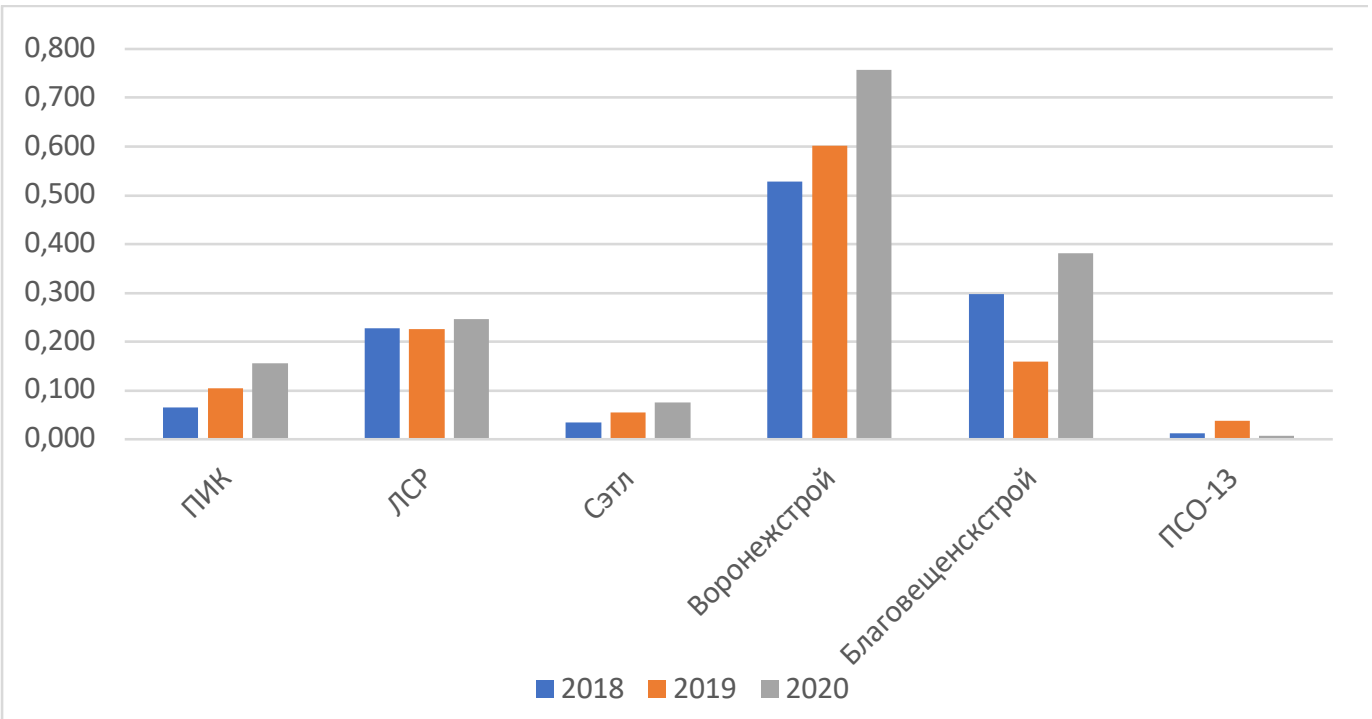

Puc. 4. Динамика коэффициента обеспеченности оборотных активов собственными средствами строительных организаций за 2018-2020 гг.

Источник: составлено авторами 


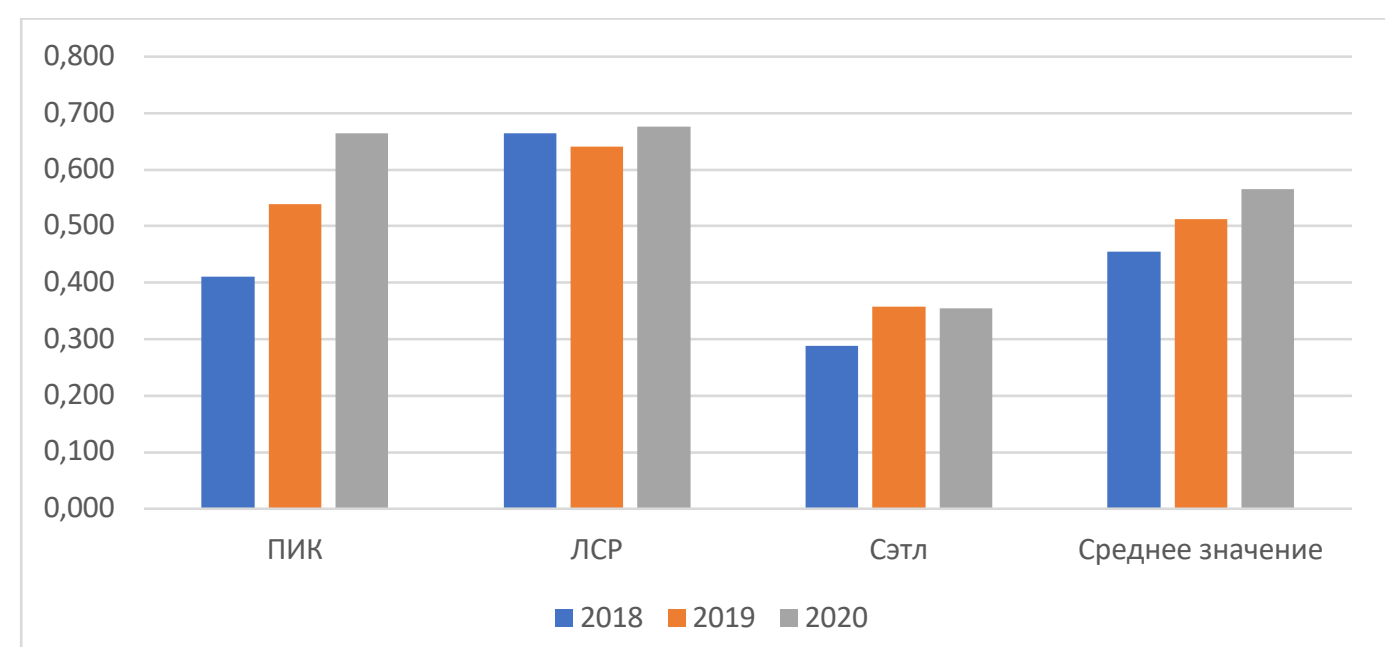

Puc. 5а. Динамика коэффициента финансовой устойчивости крупных строительных организаций за 2018-2020 гг.

Источник: составлено авторами

жению просроченной задолженности. Однако существующая сейчас динамика заболевших COVID-19 и скончавшихся от него не позволяет быть однозначно уверенными в том, что такое снижение продолжится. Скорее наоборот, следует ожидать внедрение очередных ограничений.

Данный риск может привести к финансовой неустойчивости многих строительных организаций, особенно представителей среднего и малого бизнеса, доверие к которым у населения и так относительно низкое. Поскольку продление льготной ставки может быть обусловлено только затяжной пандемией, то стоит учесть, что данный фактор может привести не только к «пузырю», но и к ряду миграционных ограничений, а также продолжению быстрого роста цен на ма- териалы (данный фактор обуславливается еще и ростом цен на нефть). И в таком случае в строительном секторе возрастут затраты на оплату труда в связи с недоступностью более дешевой иностранной рабочей силы, которая играет огромную роль в калькулировании себестоимости строительных работ, а также материальные затраты. Очередная необходимость в переводе большинства сотрудников на дистанционный режим работы накладна в данной отрасли в связи с физической спецификой выполняемых работ, контроль осуществления и администрирование которых возможен в дистанционной форме, но менее эффективен. Частично такой вывод можно сделать из исследования Центра конъюнктурных исследований Института ста-

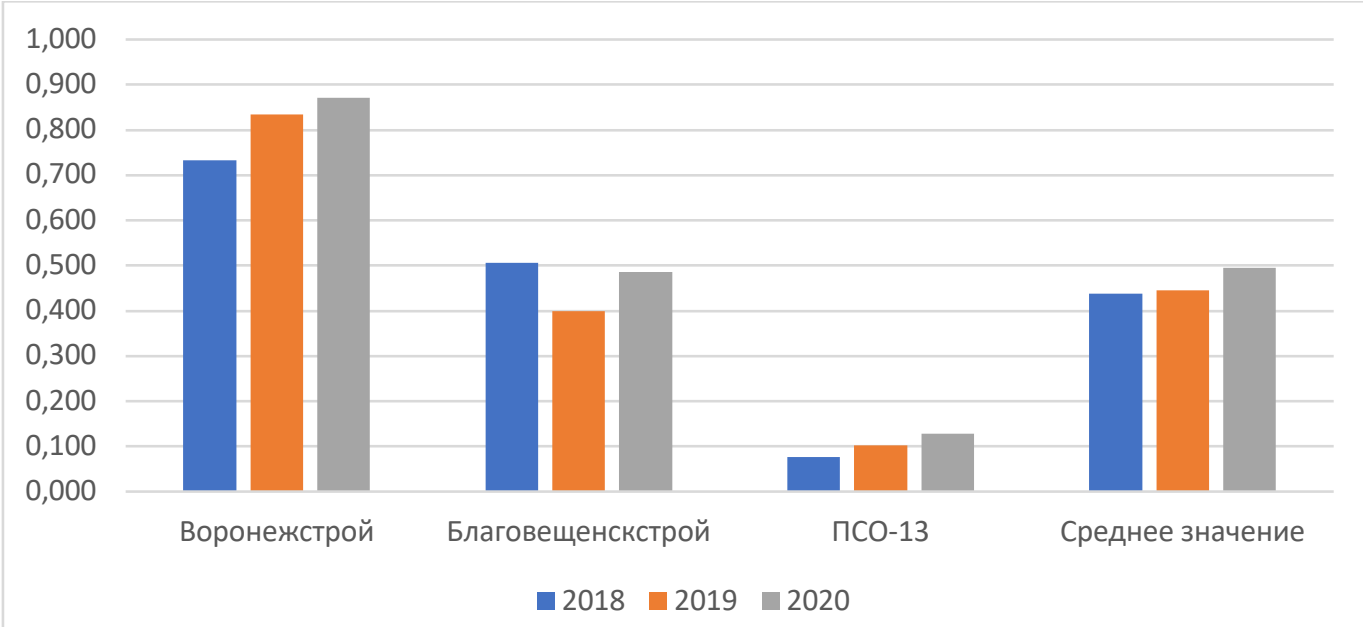

Puc. 5б. Динамика коэффициента финансовой устойчивости малых строительных организаций за 2018-2020 гг. Источник: составлено авторами 


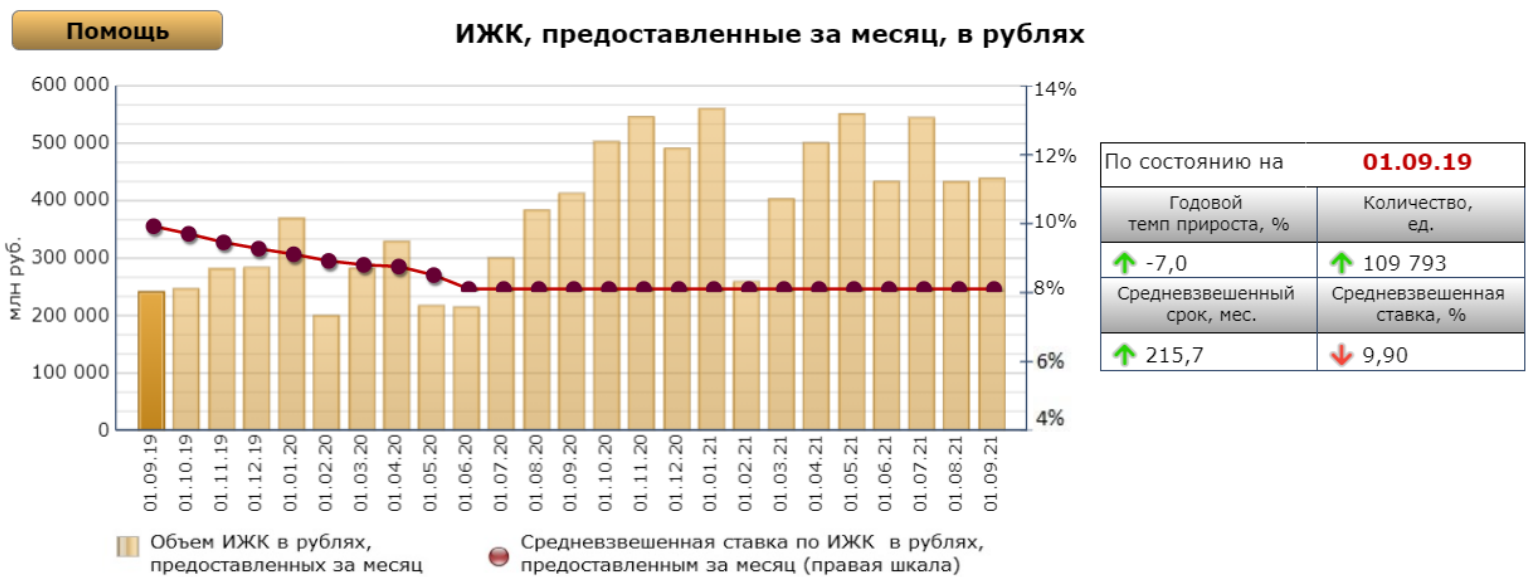

Puc. 6а. Динамика ипотечного жилищного кредитования за месяц, руб.

Источник: Центральный Банк РФ

тистических исследований и экономики знаний Национального исследовательского университета «Высшая школа экономики», в котором описана динамика Индекса предпринимательской уверенности, как показано на рисунке 7.

Данный индекс был рассчитан как среднее арифметическое значение балансов оценок уровня портфеля заказов и ожидаемых изменений численности занятых. И из его резкого спада на 9\% в середине 2020 года следует вывод о наличии проблем в строительстве как в виде сокращения количества заказов (в т.ч. прекращение уже заключенных договоров), так и в виде серьезного сокращения рабочей силы.

\section{Заключение}

Исходя из проведенного анализа финансовой устойчивости, мы видим, что в краткосрочной перспективе отрасль справляется с данными проблемами благодаря успешной деятельности в предыдущие периоды, а также кредитной политике государства, но при продолжении и так рекордной на настоящий момент отрицательной динамики на рынке строительных работ и рынке труда финансовая устойчивость может ухудшиться у многих организаций, особенно у среднего и малого бизнеса.

В целом имеют место 2 прогноза:

- если динамика заболевших COVID-19 будет снижаться и экономика постепенно будет возвращаться к доковидным показателям: строительные компании продолжат наращивать прибыль за счет роста спроса, вызванного ростом доходов населения;

- если динамика будет и дальше расти, и повлечет очередной длительный локдаун: затраты строительных организаций значительно вырастут, как и простои и переносы сроков сдачи объектов, что приведет к росту прочих расходов, а это, в свою очередь, негативно скажется на прибыли экономических субъектов строительной отрасли и их финансовой устойчивости.

В случае реализации второго варианта стоит

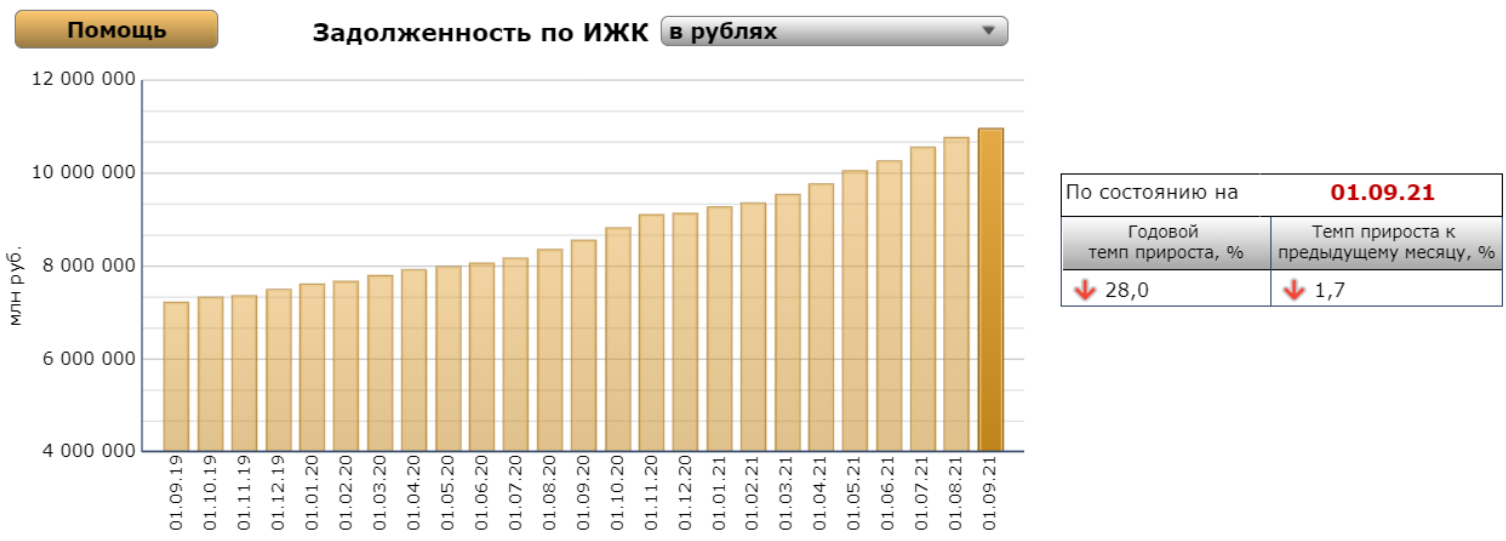

Puc. 6б. Динамика задолженности по ипотечному жилищному кредитования за месяц, руб. Источник: Центральный Банк РФ 


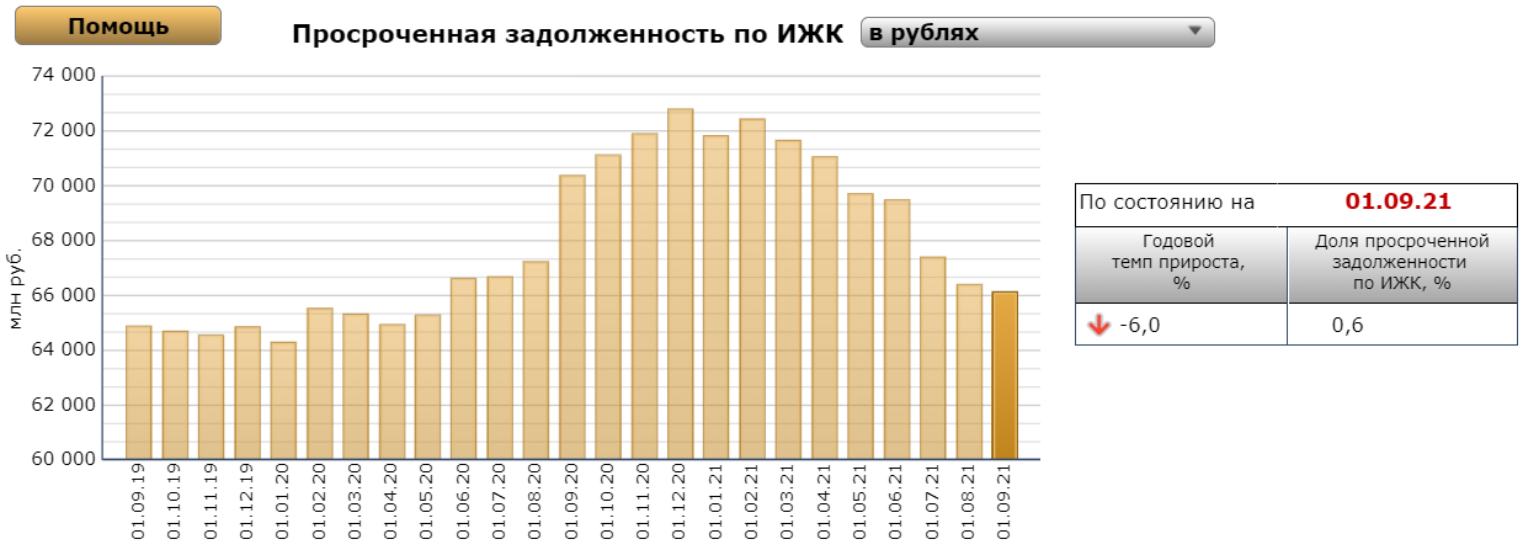

Puc. 6в. Динамика просроченной задолженности по ипотечному жилищному кредитования за месяц, руб.

Источник: Центральный Банк РФ

также взять во внимание, что возможный сценарий может привести к еще большей монополизации строительного рынка, так как малому бизнесу будет еще сложнее получить финансирование от банков, в которых они обязаны открыть эскроу-счета для осуществления долевого строительства. И такие компании будут вынуждены уйти с рынка.

Помимо прочего, строительным организациям необходимо в рамках своей деятельности стремиться к снижению имеющейся кредиторской задолженности, насколько это позволяет специфика отрасли, что повысит их ликвидность. При этом важно снижать величину и дебиторской задолженности, чтобы у организаций не было существенных потерь в условиях ин- фляции. Этому способствуют контроль сроков платежей и недопущение просрочки оплаты, а также контроль финансового состояния должников.

Повышение уровня платёжеспособности достигается путем контроля имеющихся оборотных активов у организации, а именно поступлений и расходов денежных средств, определения степени важности платежей в зависимости от того влияния, которые они оказывают на будущий финансовый результат. Необходимо наращивать объёмы и скорость движения денежных средств, чтобы организация способна была погашать имеющиеся обязательства и не решала возникающие проблемы только с помощью привлечения заёмных источников финансирования.

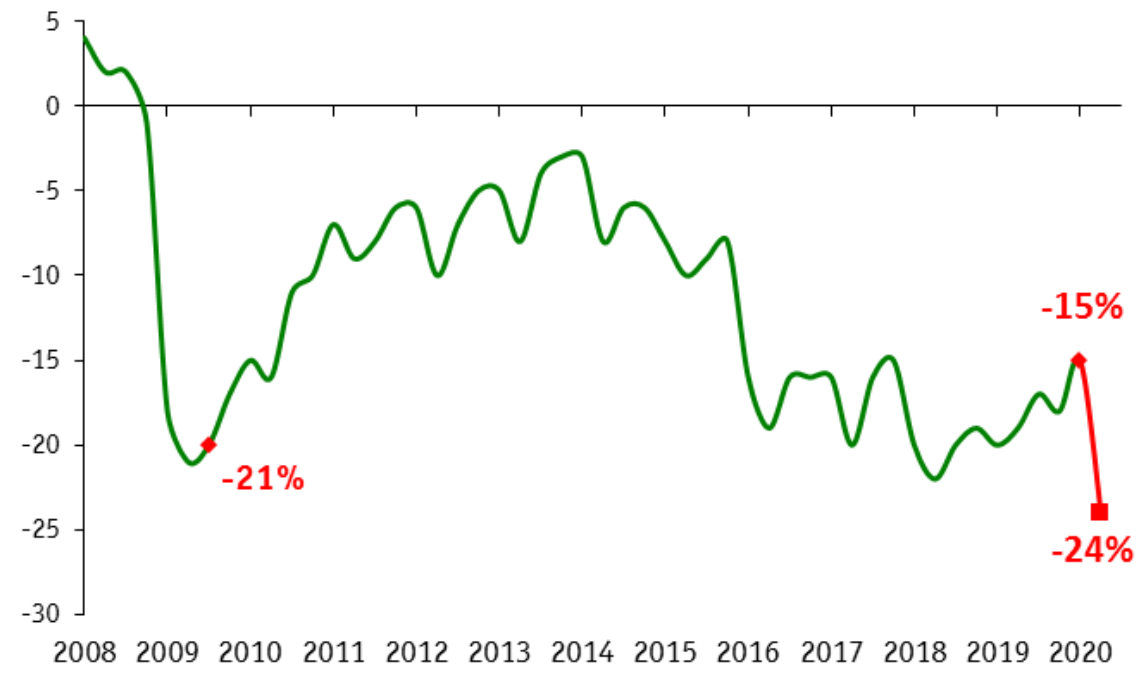

Puc. 7. Динамика Индекса предпринимательской уверенности в строительстве,\% Источник: ЦКИ ИСИЭЗ НИУ ВШЭЮ, Росстат 


\section{Библиографический список}

1. Алексеев Д. Сплошное надувательство: случится ли в России «ипотечный пузырь» / Мультимедийный информационный центр «Известия» / [Электронный ресурс] // URL: https://iz.ru/1180720/dmitrii-alekseev/ sploshnoe-naduvatelstvo-sluchitsia-li-v-rossii-ipotechnyi-puzyr / [Дата обращения: октябрь 2021 год]

2. Донцова, Л. В. Анализ финансовой отчетности: учебник / Л. В. Донцова, Н. А. Никифорова. - 7-е изд., перераб. и доп. - М.: Дело и Сервис, 2009. - 377 с

3. Иззука, Т.Б. Актуальные проблемы анализа финансовой отчетности [Текст] / Т. Б. Иззука // Наука, образование, кооперация: проблемы и перспективы развития. - М.: Издательство «Канцлер», 2017. - С. $383-387$.

4. Контроллинг и анализ: управленческий эффект: монография / Н.А. Никифорова, С. Н. Миловидова, Т. Б. Иззука, М. М.Басова; под ред. Н. А. Никифоровой. - Москва: КНОРУС, 2021. - 274 с.

5. Шнайдер, О.В., Иззука, Т.Б. Финансовые и нефинансовые показатели отчетности экономических субъектов: важность, задачи и решение. Russian Journal of Management. 2019;7(2)46-50.

6. Московские девелоперы потеряли выручку после обновления льготной ипотеки / Новостной ресурс «РИА Новости» / [Электронный ресурс] // URL: https://realty.ria.ru/20210805/developery-1744507058.html / [Дата обращения: ноябрь 2021 год]

7. Официальный сайт Единого ресурса застройщиков // URL: https://www.erzrf.ru / [Дата обращения: ноябрь 2021 год]

8. Официальный сайт Федеральной службы государственной статистики // URL: https://rosstat.gov.ru / [Дата обращения: ноябрь 2021 год]

9. Официальный сайт Центрального Банка РФ // URL: https://www.cbr.ru/ / [Дата обращения: ноябрь 2021 год]

10. Официальный сайт Центра конъюнктурных исследований Института статистических исследований и экономики знаний НИУ ВШЭ // URL: https://issek.hse.ru/dep_conres / [Дата обращения: ноябрь 2021 год]

11. Официальный сайт Центра раскрытия корпоративной информации // URL: https://www.e-disclosure.ru / [Дата обращения: ноябрь 2021 год]

12. Официальный сайт Группы «ПИК» // URL: https://pik-group.ru / [Дата обращения: ноябрь 2021 год]

13. Официальный сайт Группы «ЛСР» // URL: https://www.lsrgroup.ru / [Дата обращения: ноябрь 2021 год]

14. Официальный сайт ООО «Сэтл Групп» // URL: https://setlgroup.ru / [Дата обращения: ноябрь 2021 год] 